\title{
Biochemical studies on the characters of polyphenol oxidase from different cultivar of wheat
}

\author{
Neelam Taj ${ }^{*}$ and Syed Zahir Shah \\ Department of Botany, Islamia College University, Peshawar KP-Pakistan \\ *Corresponding author's email: Neelamtaj2013@gmail.com \\ Citation \\ Neelam Taj and Syed Zahir Shah. Biochemical studies on the characters of polyphenol oxidase from different \\ cultivar of wheat. Pure and Applied Biology. Vol. 6, Issue 4, pp1177-1188. \\ http://dx.doi.org/10.19045/bspab.2017.600126
}

\begin{tabular}{llll}
\hline \hline Received: 04/05/2017 & Revised: 09/08/2017 & Accepted: 12/09/2017 & Online First: 15/09/2017 \\
\hline \hline
\end{tabular}

\section{Abstract}

Polyphenol oxidase (PPO), is well-known to induce browning in wheat-based products. In the present study biochemical study on characteristics of PPO was done and it was observed that PPO from 10 different Pakistani wheat (Triticum aestivum $\mathrm{L}$ ) cultivars shows higher affinity towards L-DOPA, $\mathrm{pH}$ and temperature. It was found that $\mathrm{pH} 5$ shows maximum activity and $30^{\circ} \mathrm{C}$ was optimum temperature. At various temperature ranges, study was done. The enzyme was found to be stable at different temperatures up to $70^{\circ} \mathrm{C}$. Among various PPO inhibitors when tested, the most effective inhibitors for the enzyme with $10 \mathrm{mM}$ L-DOPA as substrate were EDTA and ascorbic acid. The weakest inhibitors were DDT $p$-coumeric acid, Ferulic acid, Trans-cinnamic acid, Vanillic acid and Diethyldithiocarbonate. While Cysteine was the least potent inhibitor. Sodium Chloride and Sodium bromide isoproterenol and sodium iodide $O$-phenanthroline was proved to be effective inhibitors. The effect of SDS on wheat PPOs was studied, and it was studied that PPO activity was increased in presence of $50 \mathrm{mM}$ SDS. The extraction of PPOs activity was increased by adding to the extraction buffer following alcohols methanol acetone, 2-propanol ethanol, and $\mathrm{n}$-butanol. The alcohol $\mathrm{n}$-butanol was found to be most potent alcoholic activator, 2-propanol was next to n-butanol, while the least effect was observed for ethanol and methanol.

Keywords: Triticum aestivum; Polyphenol oxidases(PPOs); Enzyme activation; Detergents; Inhibitors

\section{Introduction}

Polyphenol oxidases (PPOs) are metallo enzymes that contain copper and after production in the nucleus, PPO moves to plastid [1]. Phenolic substrates are converted to dark-coloured polyphenols (Melanin) by the action of PPO. Brown colour of chapattis and flat breads of Middle East, noodles and other end products of wheat, are considered due to PPO $[2,3]$.
Among globally cultivated cereal crops, Wheat is considered to be the most important crop. Ten thousand years ago wheat was first crop cultivated. Worldwide, $17 \%$ of the cultivated area is covered by wheat. Other cereals like Maize and Rice which are grown in humid environment while wheat crop prefers temperate region. Wheat crop is the vital food for $40 \%$ population of the world [ 4 , 5]. Wheat is grown in all parts of the world as 
compared to other cereals, as it covers more of the earth surface [6]. In 94 developing countries, Wheat is on second position after rice. The total food calories provided by it is $21 \%$. In Pakistan wheat is used in different forms like bread, breakfast cereal, Chapatti, and other various items of bakery. In East Asian nations wheat is consumed in the form of Noodles. Brown coloration is developed during storage in noodles, flour and other end products, while bright and creamy white colour is preferred by consumers [7].

In world wheat trade, the value of wheat products became a main mark in program of wheat breeding. Various physical and chemical aspects refers to the quality of wheat product as it depends on the planned purpose. The wheat grain quality is effected by different factors which are mostly categorised in to two groups, i.e chemical and physical features. In plant physiology and food science, PPO has taken much attention due to PPO adverse browning effect. Characteristics of PPO found in plant has been extensively studied in numerous vegetables, fruits, and many crops due to its importance of browning reaction in food technology and post-harvest physiology. Browning reaction can be controlled by the use of different methods. These methods include use of different substrates or extensive- range of compounds for inhibition of the enzyme, or by elimination of one of its essential constituents like, copper, enzyme and oxygen [8].

The target of present research is biochemical characterization of a wheat PPO extracted from different wheat cultivars of Pakistan, comprising affinity for PPO substrates that are used commonly and how the inhibitors effect the activity, optimum $\mathrm{pH}$, temperature and stability of $\mathrm{pH}$ was studied. Other aims of the study is influence of the detergent SDS on PPO activity were also observed along with investigation of extract from wheat PPO with MOPS buffer that may possibly be further stimulated by addition to the extract some known amounts of organic solvent like alcohol and ketone.

\section{Materials and methods \\ Plant material}

Grains of 10 different wheat cultivars (PIRSABAK 2005, SHAFAQ-06, KARWAN-2, KOHINOOR 83, KOHISTAN 97, NAEEM 82, PARWAZ 94, PASBAN 90, MIRAJ-08, SEHER-06) were obtained from Nuclear Institute of Food and Agriculture (NIFA) Tarnab KPK for their polyphenol oxidase characterization,

\section{Extraction of PPO}

Extraction of PPO was done from whole grains of wheat using standardized method [9] [10].Wheat grains were ground in liquid nitrogen and it was incubated in $1 \mathrm{ml}$ of extraction buffer (50 mM MOPS $\mathrm{pH} 6.5$, $0.2 \%$ SDS, $0.2 \mathrm{mM}$ Pefabloc 0.2\% NP-40), taken in a micro centrifuge tube and shake at (8 rpm), temperature was $4^{\circ} \mathrm{C}$ for 1 hour. After homogenization for $60 \mathrm{sec}$ the suspension was incubated again for $1 \mathrm{hr}$ in the shaker. The decanted supernatant was stored at $-80{ }^{\circ} \mathrm{C}$ after suspension was centrifuged at $4^{\circ} \mathrm{C}$ and $20,000 \mathrm{rpm}$ for 30 minutes.

\section{PPO activity assay with different substrates}

By following the same method for each cultivar the experiment was performed in triplicate. Five grains from each cultivar were kept in test tubes comprising $1.5 \mathrm{~mL}$ of phenolic substrate (Hydroquinone, Resorcinol, Phloroglucinol, $p$-coumeric acid, Ferulic acid, Vanillic acid, L-Tyrosine, Pyrocaticol,, 4-Methylcatecol, L-DOPA, Caffeic acid, Chlorogenic acid, (+) Catechin, (-) Epicatechin,phenol) made up in $50 \mathrm{mM}$ 3-( $N$-morpholino).

For phenol, incubation of tubes was done at $20^{\circ} \mathrm{C}$ and was routed at $160 \mathrm{rpm}$ for 2 hours. The tubes were incubated at $25^{\circ} \mathrm{C} \mathrm{rpm}$ for 2 hours. All the other substrates were adjusted at volume of $10 \mathrm{~m} M$ with the exemption of phenol, which was diluted at $2 \mathrm{~g} /$ lit solution. 
Succeeding to incubation, solutions part was removed from the tubes, change in absorbance was noted and compared with a control that was comprising only the particular substrate. Absorbance was recorded at $410 \mathrm{~nm}$ by spectrophotometer for catechol and phenol reactions mixtures, whereas for L-DOPA and caffeic acid reactions, absorbance changes were recorded at $475 \mathrm{~nm}$.

\section{Determination of the optimal activity}

1. Effect of $\mathbf{p H}$ on PPO activities and stabilities

The effect of $\mathrm{pH}$ on PPO enzymatic activity was studied, ranging from $\mathrm{pH} 4.0$ to 9.0. By incubating the compound in $0.05 \mathrm{M}$ phosphate ( $\mathrm{pH} 4.0$ to 9.0 ) for $30 \mathrm{~min}$, the $\mathrm{pH}$ stability was studied.

\section{Effect of temperature on PPO activity}

For finding the ideal temperature estimations of the enzyme, PPO action was measured at various temperatures ranges of $10-60{ }^{\circ} \mathrm{C}$, utilizing five substrates of phenol comprising 3, 4-dihydroxycinnamic acid (caffeic acid), phenol 3, 4-dihydroxybenzene (catechol), LDOPA and L-tyrosine. By heating the standard reaction solutions (buffer and substrate) upto proper temperature before adding of the enzyme, thus impact of temperature on the action of PPO was noted.

\section{Thermal stability of PPO}

The thermal denaturation of the purified enzyme was learned at $35^{\circ} \mathrm{C}, 55^{\circ} \mathrm{C}$, and 75 ${ }^{\circ} \mathrm{C}$. One $\mathrm{mL}$ of standard reaction solution at temperature that is required in a test tube, was incubated for settled time intervals. Required time interval was reached, the test tube was kept in an ice bath to cool down. At $25^{\circ} \mathrm{C}$ the activity of the enzyme was measured.

\section{Effect of inhibitors on PPO activity}

For the study of PPO inhibitors on PPO activity in each sample, $2 \mathrm{~mL}$ micro centrifuge tube was taken and 5 grains were placed in it and pre incubated for thirty minutes in $1.50 \mathrm{~mL}$ with a given inhibitor (Table 1) in $50 \mathrm{mM}$ MOPS, at $\mathrm{pH}$ of 6.5 , with 0.02 percent Tween- 20 (volume/volume) and kept at room temperature of $25{ }^{\circ} \mathrm{C}$ with continuous mixing. Following pre incubation, $0.25 \mathrm{~mL}$ of $10 \mathrm{mM}$ L-DOPA was added. The PPO activity was measured.

Table 1. Substrate specificity of PPO in wheat

\begin{tabular}{|l|c|}
\hline Substrate & Relative activity (\%) \\
\hline Hydroquinone & 0 \\
\hline Resorcinol & 0 \\
\hline Phloroglucinol & 0 \\
\hline$p$-coumeric acid & 0 \\
\hline Ferulic acid & 0 \\
\hline Vanillic acid & 0 \\
\hline L-Tyrosine & 25.0 \\
\hline Pyrocaticol & 22.6 \\
\hline 4-Methylcatecol & 15 \\
\hline L-DOPA & 100 \\
\hline Caffeic acid & 5.0 \\
\hline Chlorogenic acid & 4.5 \\
\hline (+)Catechin & 10.7 \\
\hline (-)Epicatechin & 30.8 \\
\hline
\end{tabular}


PPO assays for the evaluation of SDS impact on PPO extraction and activity

For the assessment of SDS influence on PPO action and extraction, PPO from wheat cultivar was separated with $500 \mathrm{~L}$ medium of extraction comprising of MOPS buffer 50 $\mathrm{mM}$. with $6.5 \mathrm{pH}$, and $0-100 \mathrm{mM}$ SDS. The PPO activity was measured.

PPO assays for the evaluation of organic solvent impact on activity of PPO and its extraction

Wheat grain PPO was extracted with Phosphate buffer comprising of chemical compounds to study the effect of these additives. Arrangements of different concentration of the organic solvents were set up in the MOPS buffer $(50 \mathrm{mM})$ at $6.5 \mathrm{pH}$. Buffer of $50 \mathrm{mM}$ MOPS containing 1-40 percent (Volume/Volume) of methanol, ethanol, 2-propanol and n-butanol, were likewise arranged. These chemicals were then separately utilized for the extraction of PPO to study their impacts on the enzymatic activity. The PPO action was measured.

\section{Results and discussion}

Colour is an imperative component characteristic of products made up of wheat and polyphenol oxidase (PPO) is thought to be responsible and have noteworthy part in their detrimental browning reactions. The enzymatic reaction regularly happens in wheat end product and is the reason for an abatement in their sensory properties and dietary value

\section{pH effect on enzyme activity in wheat}

In the present study optimum $\mathrm{pH}$ of the purified enzyme was examined. By using LDOPA as substrate, the activity of purified PPO from wheat grains was measured at different $\mathrm{pH}$ values. The result is shown in Figure 1. It was studied that ideal $\mathrm{pH}$ for the purified enzyme was $\mathrm{pH} 5$ in 10 cultivars. It was reported, that the optimum $\mathrm{pH}$ on which PPO shows maximum activity was 5 (Figure 1). The enzyme activity range was studied and it was noted that PPO was active between the $\mathrm{pH}$ range 4.5-9.0, and showed highest activity range at $\mathrm{pH} 5.0$ while at $\mathrm{pH} 6$ it showed half maximal activity. Its activity decreased speedily at $\mathrm{pH}$ 8.0. On the other hand, at $\mathrm{pH} 7.5$ and $9.0,50 \%$ of its activity was lost after $7.5 \mathrm{pH}$ and no activity were noted when $\mathrm{pH}$ crossed the limit of $9 \mathrm{pH}$ (Figure 1) .Our results are similar to the results of Gao et al. [11]. The $\mathrm{pH}$ effect on PPO activity has been extensively studied in different plants, in most cases optimum $\mathrm{pH}$ was reported between 4.0 and 8.5 , it was found that the pureness of enzyme and the form of buffer both have effect on the optimum $\mathrm{pH}[12,13]$.

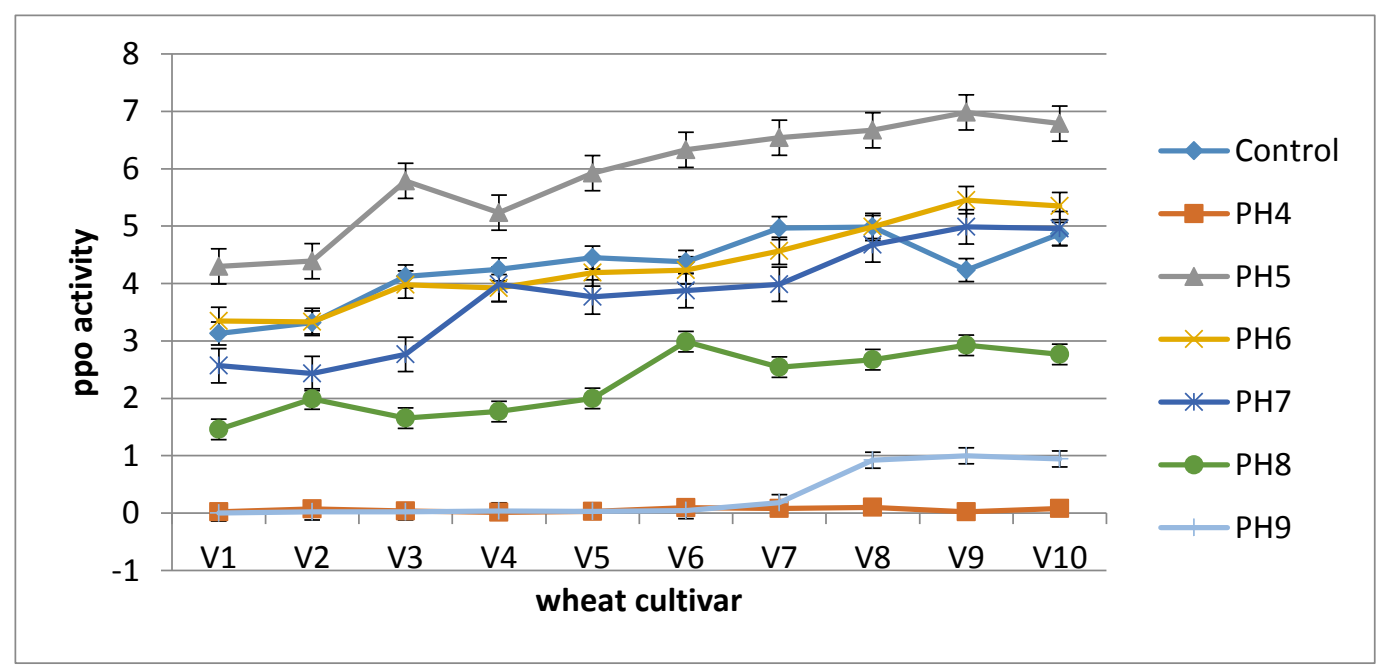

Figure 1. Showing activity of wheat PPO as a function of $\mathrm{pH}$ 
Temperature influence on PPO and its stability towards temperature

To study the influence of different temperatures on PPO activity in wheat grain it was studied that action of PPO increases slowly from 10 to $20^{\circ} \mathrm{C}$, above $30^{\circ} \mathrm{C}$ higher rate of activity was observed. The ideal temperature for PPO activity was also investigated and it was found that at $30^{\circ} \mathrm{C}$ PPO activity reaches to its maximum level (Figure 2). It was reported that when the temperature limit increased from $40^{\circ} \mathrm{C}$, the activity started to decrease, and PPO completely became inactive when temperature limits reached to $60^{\circ} \mathrm{C}$ and $70^{\circ} \mathrm{C}$ as shown in Figure 3. It has been reported by many authors that PPO is unaffected by temperature up to $90^{\circ} \mathrm{C}[14,15]$. Previously it has been reported that the temperature has effects between $10{ }^{\circ} \mathrm{C}$ and $80^{\circ} \mathrm{C}$ on $\mathrm{PPO}$ action of durum wheat. They further concluded that filtered durum wheat PPO has an ideal activity at $40^{\circ} \mathrm{C}$. They also reported protein denaturation due to slow reduction in enzyme activity after $40^{\circ} \mathrm{C}$ temperature [16].

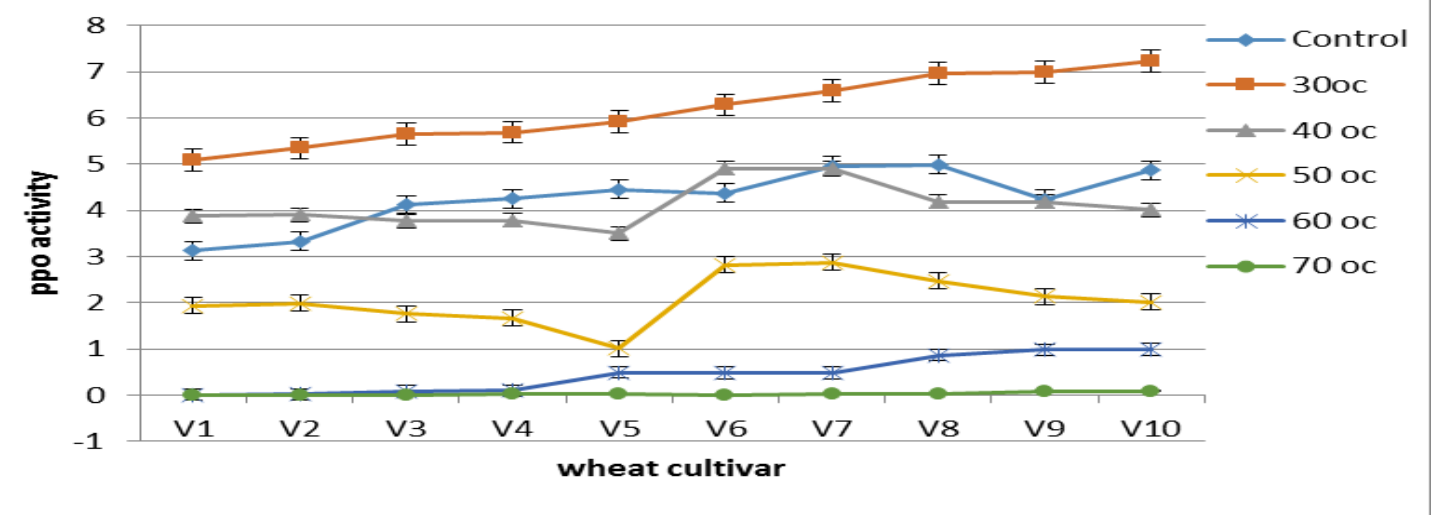

Figure 2. Showing activity of wheat PPO as a function of temperature

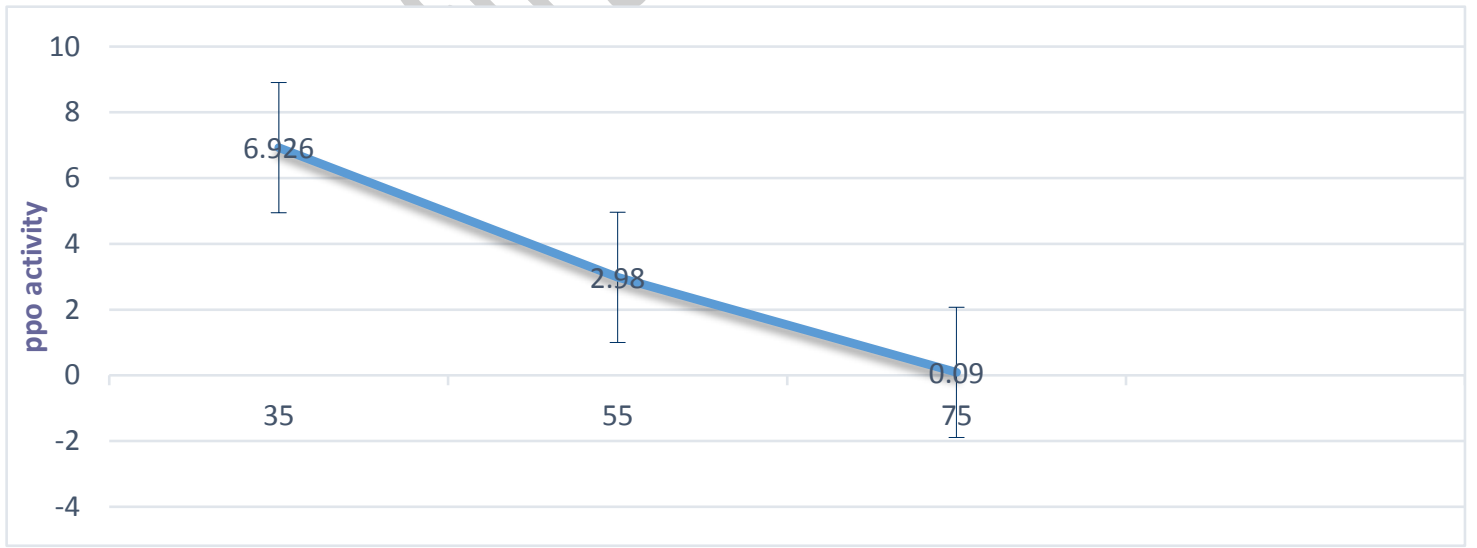

Figure 3.Activity of wheat PPO as a function of temperature stability. Each data point is the mean of two determinations. The vertical bars represent standard deviations

PPO activity assay with different substrates
Primary substrates of PPO are Phenolic compounds. In different plant sources PPO 
shows different types and relative concentrations of natural phenols. To define the substrate specificity for the purified enzyme at $\mathrm{pH} 6$, different substrates were studied and compared. The result are shown in Table 1. The PPO shows highest activity for L-DOPA because it was oxidized to Ltyrosine and diphenols. Chemical nature of the given substrate has great effect on PPO activity (Table 1). Different substrates shows different oxidising ratesfor PPO and therefore divided into three categories i.e, (a) un oxidizable, (b) slowly oxidizable (c) readily oxidizable. Hydroquinone, Resorcinol, Phloroglucinol, $p$-coumeric acid, Ferulic acid and Vanillic acid were not good substrates and were unoxidizable subsrtae, while in the present study L-Tyrosine, Pyrocaticol showed slowly oxidizable substrate level activity. On the other hand 4Methylcatecol, Caffeic acid, Chlorogenic acid, (+) Catechin, (-) Epicatechin,phenol were found to have readily oxidizable substrate level activity, while the most potent oxidizable substrate was L-DOPA. In a research work it was studied that, PPO extract from wheat bran shows differences in the oxidation rates for different phenolic substrates, it was also reported that some of them like ferulic acid, caffeic acid and chlorogenic acid are slowly oxidizable phenolics while 3-phenyl-2-propenoic acid was characterized as unoxidizable [17].
According to one study, different substrates like, L-DOPA phenol, catechol, caffeic acid methylcatechol and tyrosine when tested for best substrate, catechol and L-DOPA were found to be the best substrates [18]. Many names are given to Polyphenol oxidase because various substrates are catalysed by it, the top central of which are epicatechin, catechin L-DOPA, L-tyrosine, chlorogenic acid, methylcatechol, and pyrocatechol, among all of these the best substrates are LDOPA and catechol $[19,18]$.

\section{pH stability}

The (Figure 4) shows dependence of PPO activity on $\mathrm{pH}$. It has been standardized at $\mathrm{pH}$ 4.0 to 8.5 over a time of 4 days by utilizing substrate L-DOPA. It was show in (Figure 4) that PPO enzymatic activity of wheat at $\mathrm{pH}$ 5.5 was the most intrusting it recommends that the compound is exceptionally unsteady at increase of $\mathrm{pH}$, but no action subsequently at $\mathrm{pH}$ of 8.5 for 1 day, and a significant decrease in action of enzyme was noted at $\mathrm{pH}$ 8.0 (Figure 4). The outcomes of the present study are like Ziyan and Turk [20] who reported the ideal $\mathrm{pH}$ series was observed to be 4.5-8.2 for PPO of plants. In another study it was explained that the ideal $\mathrm{pH}$ for PPO of durum wheat was observed to be 6.5. Their outcomes reported that the best $\mathrm{pH}$ of durum wheat PPO is like PPOs from different sources. PPO of durum wheat was observed to stable in the $\mathrm{pH}$ from 6.0 to 6.8 [16].

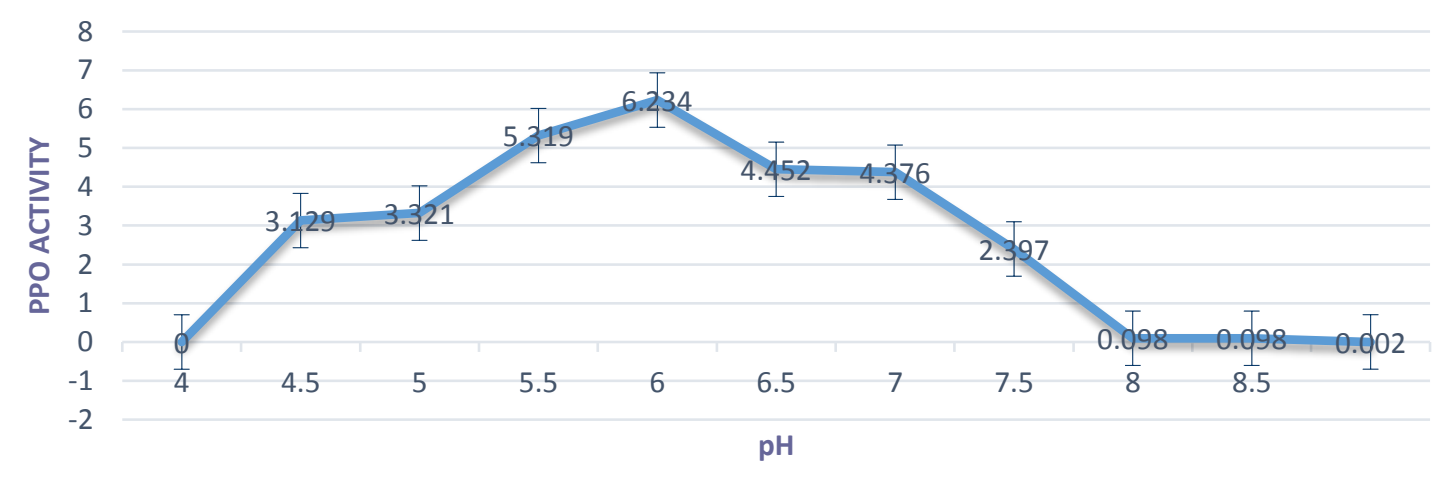

Figure 4. Activity of wheat PPO as a function of pH stability. Each data point is the mean of three determinations. The vertical bars represent standard deviations 


\section{Effect of SDS on PPO extraction and activity}

The current research has additionally shown that PPO of wheat activity is affected by solid SDS which is anionic detergents. Figure 5 shows the SDS effect on PPO extraction and activity. SDS extraordinarily improved extraction of wheat PPO up to $50 \mathrm{mM}$ while activity diminishes steadily as dose increases (Figure 5). PPO activity is present mostly in the external coatings of wheat portions (grain), and little activity is available in processed flour [21-22]. In this manner, it is hard to measure these compounds with particular range of spectrophotometry utilizing typical substrates, for example, LDOPA, catechol, phenol, tyrosine, and methyl catechol [18]. Subsequently an impact of the solid anionic detergents SDS on PPO action from a few other species has been depicted before and a current report likewise demonstrates that this detergents has impact on PPO activity removed from wheat and its action increases with SDS [23].

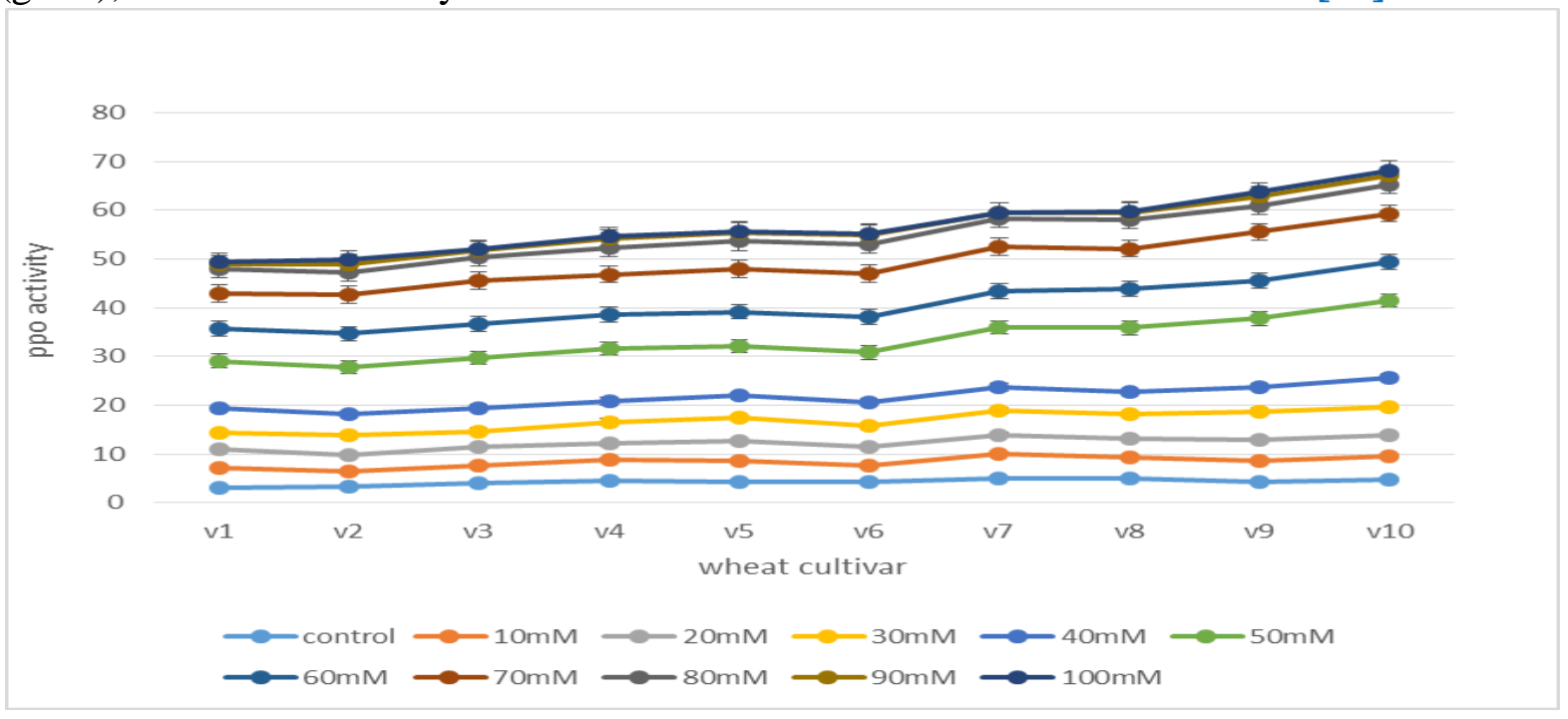

Figure 5. Showing effect of SDS on PPO activity in different wheat cultivar

\section{Effect of inhibitors on activity of PPO}

The impact of inhibitors on PPO activity has been contemplated since the primary reviews on PPO. Few inhibitors have been studied yet, in the present study, a number of inhibitors have been tested and it was found that the most weak inhibitors were Transcinnamic acid, Diethyldithiocarbonate, pcoumeric acid, Ferulic acid, Vanillic acid and DDT (Table 2). While the EDTA and ascorbic acid were the strongest inhibitors and Cysteine was the least potent inhibitor. Sodium Chloride, Sodium bromide Isoproterenol and sodium iodide $O$ phenanthroline were proved to be the effective inhibitors (Table 2). Our results are similar to the study of Madani et al. [24] and
Gao et al. [11], who demonstrated that the PPO activity from Cleome gynandra was marginally expanded by 0.1 percent SDS, intensely hindered by $\mathrm{Hg} 2+$ and $\mathrm{Pb} 2+$, and totally repressed by $1.0 \mathrm{mM}$ of ascorbic acid, L-cysteine, b-mercaptoethanol, sodium diethyldithiocarbamate and thiourea, and by $10 \mathrm{mM}$ of dithioerythritol, sodium sulphite and sodium metabisulphite. According to the findings of Queiroz et al. [13] the PPO obtained from cashew apple (Anacardium occidentale L.) was reported that sodium chloride increase PPO action while ascorbic acid, citrus extract, sodium sulphite and sodium metabisulphite diminished PPO activity. 
Table, 2. Effect of inhibitor on purified wheat PPO

\begin{tabular}{|l|l|}
\hline Inhibitor & Relative activity inhibition (\%) \\
\hline Ascorbic acid & 100 \\
\hline Diethyldithiocarbonate & 0 \\
\hline 2,2-dipyridyl & 88.7 \\
\hline$O$-phenanthroline & 72.2 \\
\hline Thiourea & 15.9 \\
\hline Sodium azide & 11.2 \\
\hline EDTA & 99.1 \\
\hline Cysteine & 50.1 \\
\hline Glutatione, reduced form & 63.6 \\
\hline Iodoacetic acid & 25.4 \\
\hline Sodium fluoride & 9.3 \\
\hline Sodium Chloride & 73.8 \\
\hline Sodium bromide & 78.8 \\
\hline Sodium iode & 75.0 \\
\hline Trans-cinnamic acid & 0 \\
\hline$p$-coumeric acid & 0 \\
\hline Ferulic acid & 0 \\
\hline Vanillic acid & 0 \\
\hline ethyl alcohol & 11.2 \\
\hline DDT & 0 \\
\hline Isoproterenol & 55.7 \\
\hline
\end{tabular}

\section{Effect of organic compounds on PPO extraction and activity}

To focus on the effect of ketones on activity of PPO, study showed that Acetone from 1 to 20 percent in the extraction buffers had little effect on PPO activity in grain from ten wheat cultivars (Figure 6) and with just a minor increase at 40 percent in. To test the Alcohols effects on MOPS Buffer on activity of PPO, four alcohols (Ethanol, Methanol, 2-propanol and n-butanol) were examined independently. The aftereffects of PPO action in the liquor extraction are presented in Figure 6, 7, 8, 9, 10. Methanol had ignorable impact on PPO action. Indeed, there was a minor diminishing in the activity as the amount of methanol was increased, but at 40 percent rise in PPO activity was noted (Figure 6). There was no observable effect on PPO activity when ethanol up to 20 percent was used (Figure 7). Ethanol and 2-propanol extracts carried on in fact a similar way, with unremarkable rise in the PPO activity at 40 percent fixation (Figure 8,9). The maximum noteworthy effect of alcoholic amount on PPO activity in wheat grain was noted by using n-butanol. The particular increase in the activity of PPO was seen in n-butanol for all wheat cultivars (Figure 10). Our outcomes are similar with Okot Kotber et al. [17]. 


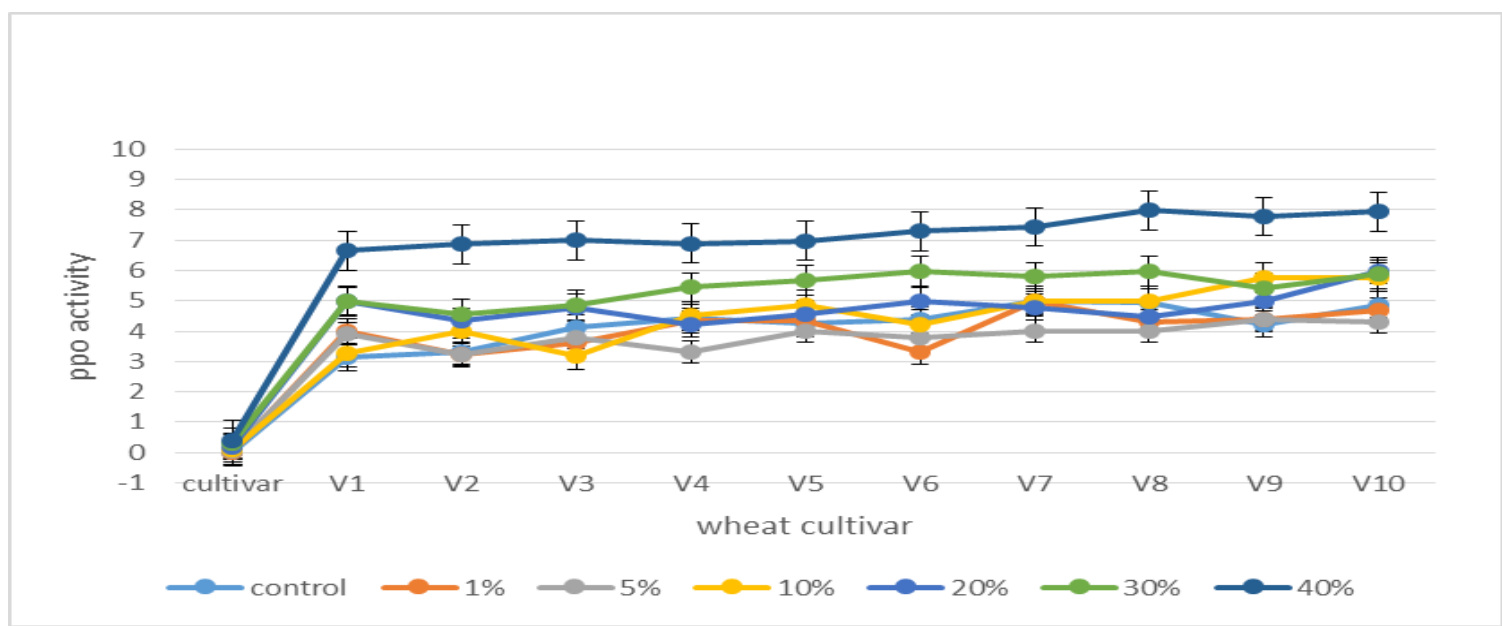

Figure 6. Showing effect of organic solvent (acetone) on PPO activity in different wheat cultivar

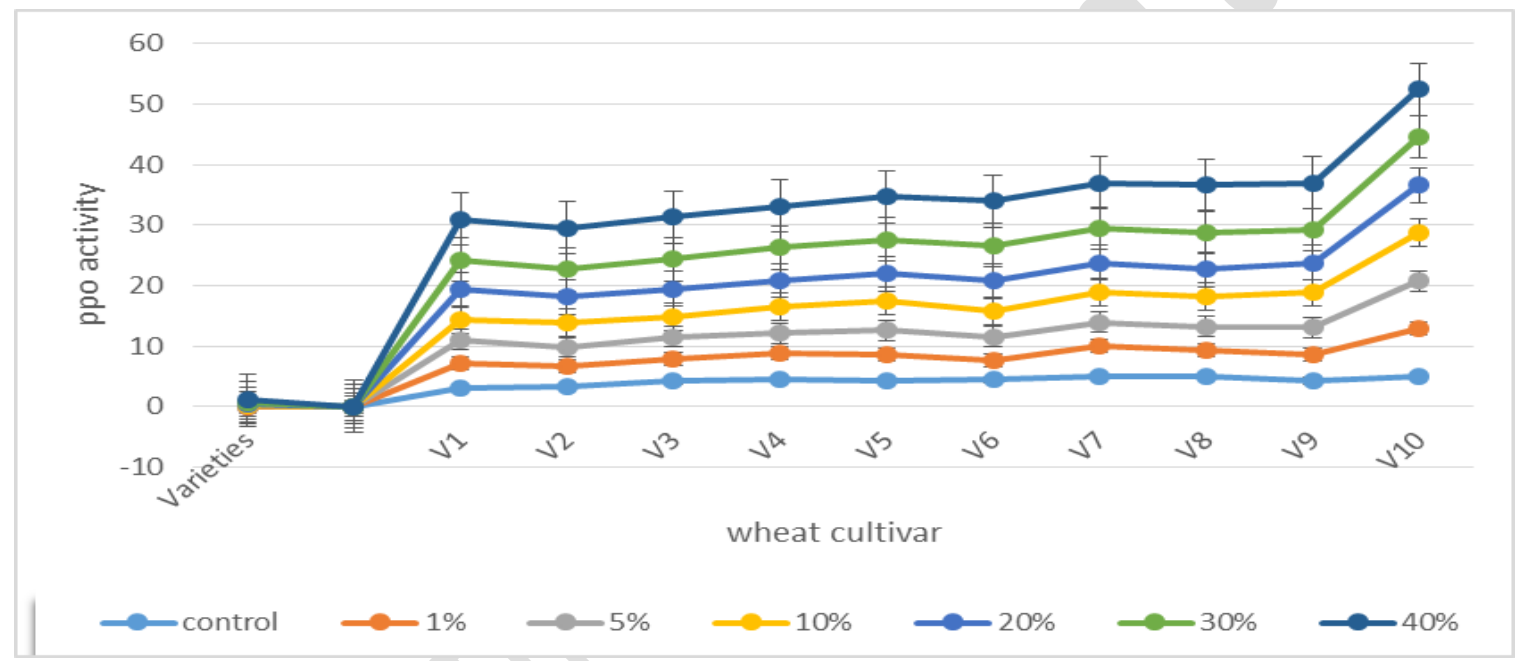

Figure 7. Representing effect of organic solvent (methanol) on PPO activity in different wheat cultivar

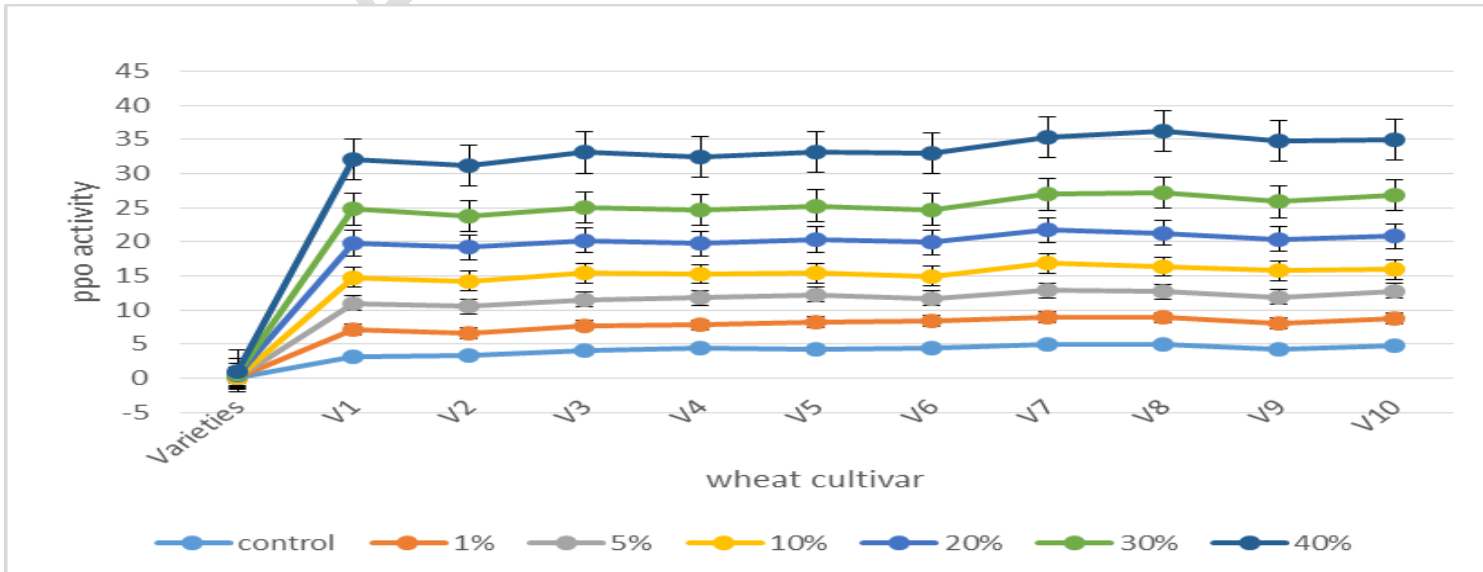

Figure 8. Represents effect of organic solvent (ethanol) on PPO activity in different wheat cultivar 


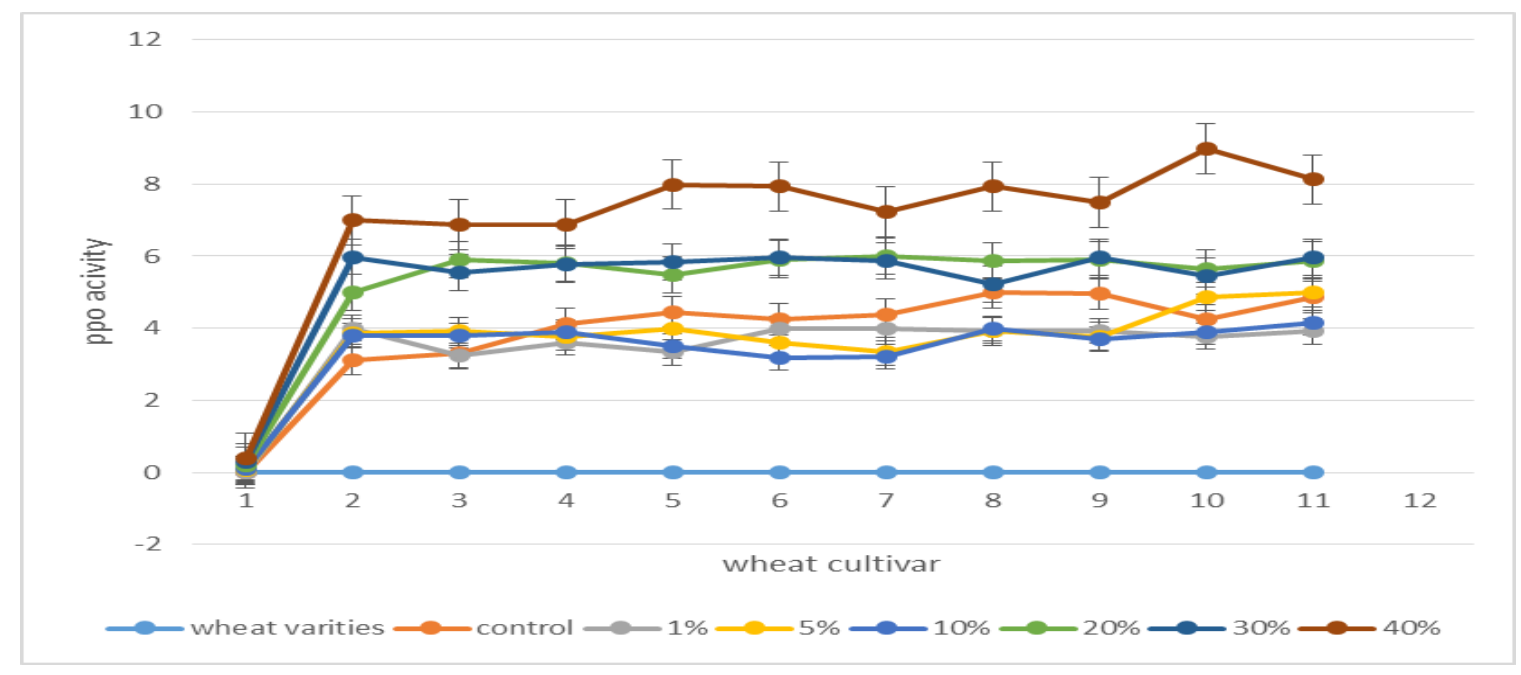

Figure 9. Effect of organic solvent (isopropanol) on PPO activity in different wheat cultivar

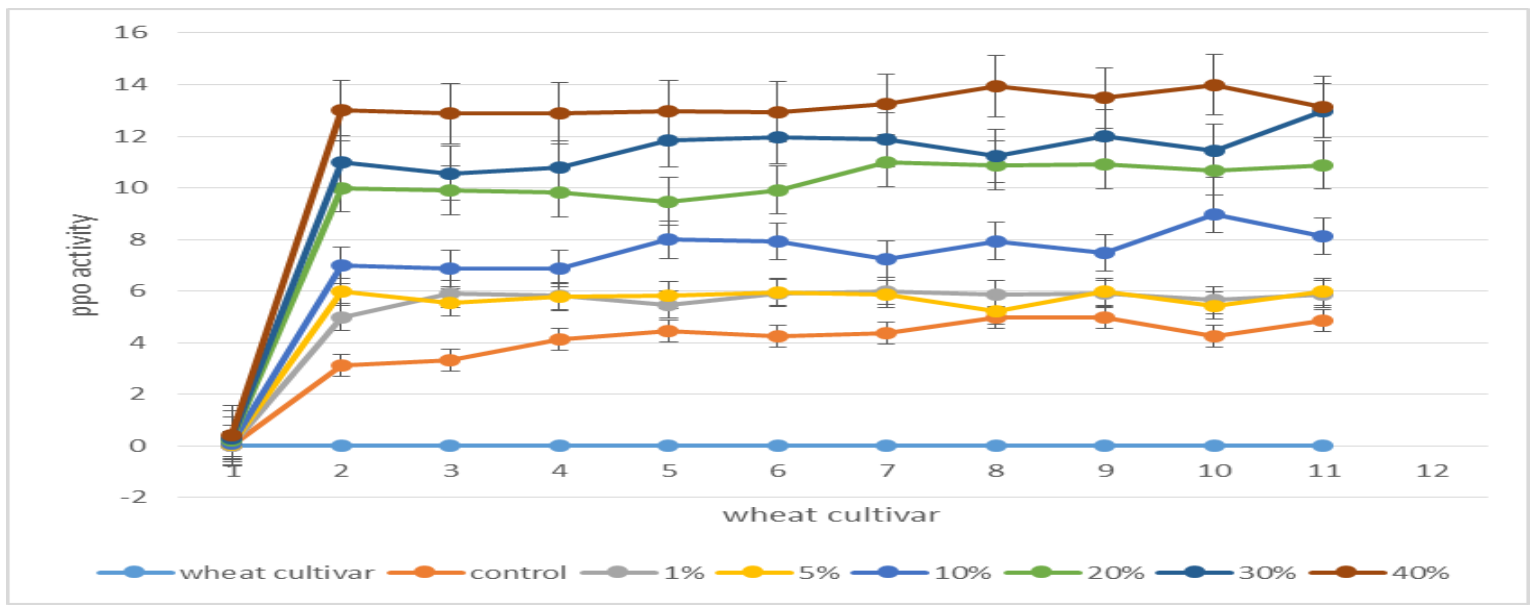

Figure 10. Effect of organic solvent (n-butanol) on PPO activity in different wheat cultivar

\section{Conclusion}

The existing research study was completed to study the interesting biochemical characteristics of PPOs in wheat grains. Biochemical characterization of wheat PPO extracted from different wheat cultivars of Pakistan. It was examined that best substrates for PPO was L-DOPA, while EDTA and ascorbic acid were the strongest inhibitors. Further it was found out that optimum $\mathrm{pH}$ was 5 and at $30^{\circ} \mathrm{C}$ of temperature, $\mathrm{PPO}$ activity reaches to its maximum. In the light of our research findings, it seems possible that these proteins are mostly layer bounded. The extraction of PPO can be impressively enhanced by utilizing generally larger amounts of SDS. Furthermore, PPO separated from high-activity wheat lines without detergent can be enhanced by SDS. The extraction of PPOs activity could be increased by adding 2-propanol, methanol, acetone, ethanol, and $\mathrm{n}$-butanol in the extraction buffer.

\section{Authors' contributions}

Conceived and designed the experiments by $\mathrm{N}$ Taj \& SZ Shah, Performed the Experiments by N Taj, Analyzed the Data N Taj, Contributed reagents/ materials/ analysis tools: N Taj \& SZ Shah, Wrote the paper: N Taj. 


\section{Acknowledgement}

This study is a part of Ph.D work of the first author and she is thankful to all those who helped her in this regard.

\section{Referances}

1. Anderson JA \& Morris CF (2003). Purification and analysis of wheat grain polyphenol oxidase (PPO) protein. Cereal Chemistry 80: 135-143.

2. Kruger JE, Morgan B, Matsuo RR \& Preston KR (1992). A comparison of methods for the prediction of Cantonese noodle color. Plant Sci 72: 1021-1029.

3. Morris CF, Jeffers $\mathrm{HC} \&$ Engle DA (2000). Effect of processing, formula and measurement variables on alkaline noodle color toward an optimized laboratory system. Cereal Chem 77: 77Đ85.

4. Goyal, A \& Prasad R (2010). Some Important Fungal Diseases and their Impact on wheat Production. In: Arya A, Perelló AEV (eds) Management of fungal plant pathogens. CABI (H ISBN 9781845936037): pp.362.

5. Peng JD, Sun E \& Nev (2011). Wild emmer wheat, Triticum dicoccoides, occupies a pivotal position in wheat domestication. AJCS 5: 1127-1143.

6. Kayani AK, Qureshi S, Kayani WK, Qureshi R, Waheed A, Arshad M, Gulfraz M \& Laghari MK (2010). Assessment of wheat yield potential after cropping mungbean (Vigna radiate (L.) Wilczek). Pak J Bot 42(3): 1535-1541.

7. Kruger JE, RR Matsuo \& KA Preston (1992). A comparison of methods for the prediction of Cantonese noodle color. Can. J Plant Sci 72: 1021-1029.

8. Gross C, Bervas E, Chanliaud G \& Charmet G (2007). Genetic analysis of bread making quality scores in bread wheat using a recombinant inbred line population. Theor Appl Genet 115: 313323.

9. Anderson JL, Schingoethe DJ, Kalscheur KF \& Hippen AR (2006). Evaluation of dried and wet distillers' grains included at two concentrations in the diets of lactating dairy cows. J. Dairy Sci 89 (8): 3133-3142.

10. Fuerst EP, Anderson JV, Morris CF, (2006a). Polyphenol oxidase in wheat grain. Whole-kernel and bran assays for total and soluble activity. Cereal Chemistry 83, 10-16.

11. Gao Z, Liu J \& Xiao X (2011). Purification and characterisation of polyphenol oxidase from leaves of Cleome gynandra L. Food Chemistry 129: 1012-1018.

12. Erat M, Sahin YN, Aksoy G \& Demirkol A (2010). Partial characterization of polyphenoloxidase from a hybridized wheat (Triticum aestivum L.). European Food Research and Technology 231: 899-90.

13. Queiroz C, Ribeiro da Silva A, Mendes Lopes M, Fialho E \& Valente-Mesquita V (2011). Polyphenol oxidase activity, phenolic acid composition and browning in cashew apple (Anacardium occidentale L.) after processing. Food Chemistry 125: 128-132.

14. Soysal C \& Soylemez Z (2004). Properties of wheat bran polyphenol oxidase. Nahrung/Food 48: (1) 5-8.

15. Kayani WK, Majid SA, Mahmood T, Naqvi SMS \& Waheed A (2011). Effect of temperature stress on polyphenol oxidase activity in grains of some wheat cultivars. Pak J Bot 43(2): 1011-1020.

16. Altunkaya A \& Gökmen V (2012). Partial purification and characterization of polyphenoloxidase from durum wheat (Triticum durum L.). Journal of Cereal Science 55: 300-304.

17. Okot Kotber M, Liavoga A, Yong KJ \& Bagorogoza K (2001). Activity and inhibition of polyphenol oxidase in extracts of bran and other milling fractions from a variety of wheat cultivars. Cereal Chem 78(5): 514-520. 
18. Anderson JA \& Morris CF (2001). An improved whole-seed assay for screening wheat germplasm for polyphenol oxidase activity. Crop Science 41: 1697-1705.

19. Kihara T, Murata M, Homma S, Kaneko S \& Komae K (2005). Purification and characterization of Wheat (Triticum aestivum) Polyphenol Oxidase. Food Sci Technol Res 11(1): 87-94.

20. Ziyan E \& Turk SP (2004). Purification and characterization of Pear (Pyrus communis) Polyphenol Oxidase. Turk $J$ Chem 28: 547-557.

21. Demeke T, Morris CF, Campbell KG, King GE, Anderson JA \& Chang HG (2001). Wheat polyphenol oxidase: distribution and genetic mapping in three inbred line populations. Crop Sci 41: 1750-1757.
22. Rani KU, Rao UJSP, Leelavathi K \& Rao PH (2001). Distribution of enzymes in wheat flour mill streams. J Cereal Sci 34:233-242.

23. Okot Kotber M, Liavoga A, Yong KJ \& Bagorogoza K (2002). Activation of Polyphenol Oxidase in Extracts of Bran from Several Wheat (Triticum aestivum) Cultivars Using Organic Solvents, Detergents, and Chaotropes. Agric Food Chem 50: 2410-241.

24. Madani I, Lee P \& Hung L (2011). Partial Purification and Characterisation of Polyphenol Oxidase from Hibiscus rosasinensis L. 2nd International Conference on Biotechnology and Food Science IPCBEE 7. 